\title{
POSITIVE AND NEGATIVE SUDDEN IMPULSES CAUSED BY FAST FORWARD AND REVERSE INTERPLANETARY SHOCKS
}

\author{
Vânia Fátima Andrioli ${ }^{1}$, Ezequiel Echer ${ }^{2}$, Jairo Francisco Savian ${ }^{3}$ and Nelson Jorge Schuch ${ }^{4}$ \\ Recebido em 22 dezembro, 2005 / Aceito em 12 junho, 2006 \\ Received December 22, 2005 / Accepted June 12, 2006
}

\begin{abstract}
Fast forward interplanetary shocks (FFS) are characterized by positive jump in all interplanetary plasma parameters (solar wind speed, temperature and density) and interplanetary magnetic field. However the fast reverse interplanetary shocks (FRS) are characterized by negative jump in all mentioned parameters except solar wind speed. Observations show that FFS cause positive sudden impulses (SI) while FRS cause negative SI in the H-component of the geomagnetic field. In this work we investigate the SI caused by interplanetary shocks. We use the observed plasma parameters, upstream and downstream, to calculate the variation of dynamic pressure. We observe that the SI amplitude is larger for positive SI than for negative ones, as a consequence of the fact that FFS have larger dynamic pressure variations as compared to FRS.
\end{abstract}

Keywords: Solar wind, interplanetary shock waves, sudden impulses, magnetosphere.

RESUMO. Choques interplanetários do tipo frontal rápido (FFS) são caracterizados por uma descontinuidade súbita positiva em todos os parâmetros de plasma interplanetário (velocidade, temperatura e densidade do vento solar) e campo magnético interplanetário. Os choques do tipo reverso rápido (FRS) possuem descontinuidade súbita negativa em todos os parâmetros exceto a velocidade do vento solar. Observa-se que os FFS causam impulsos súbitos (SI) positivos e os FRS causam SI negativos na componente H do campo magnético terrestre. Neste trabalho realizou-se um estudo destes impulsos súbitos, causados por choques interplanetários. Utilizaram-se os parâmetros de plasma, antes e depois do choque, para calcular a variação da pressão dinâmica. Observou-se que os Sls são maiores quando causados por FFS que quando formados por FRS, isto porque os FFS possuem maior variação na pressão dinâmica que os FRS.

Palavras-chave: Vento solar, ondas de choque interplanetárias, impulsos súbitos, magnetosfera.

\footnotetext{
${ }_{1}^{1}$ Space Science Laboratory of Santa Maria - LACESM/CT - UFSM, Campus da Universidade Federal de Santa Maria - UFSM, Centro Tecnológico - LACESM - Cidade Universitária, 97105-900 Santa Maria, RS, Brazil. Phone: +55 (54) 3525-1066 or 3525-1171; Fax: +55 (54) 3525-1171 - E-mail: vaniafatima@gmail.com ${ }^{2}$ National Institute for Space Research - INPE - MCT, Av. dos Astronautas, 1758 - Jd. Granja, 12227-010 São José dos Campos, SP, Brazil. Phone: +55 (12) $3945-6000$ -E-mail: eecher@dge.inpe.br

${ }^{3}$ Space Science Laboratory of Santa Maria - LACESM/CT - UFSM, Campus da Universidade Federal de Santa Maria - UFSM, Centro Tecnológico - LACESM, Cidade Universitária, 97105-900 Santa Maria, RS, Brazil. Phone: +55 (55) 3220-8021 or 3220-8781; Fax: +55 (55) 3220-8007 - E-mail: savian@lacesm.ufsm.br ${ }^{4}$ Southern Regional Space Research Center - CRSPE/INPE - MCT, Campus da Universidade Federal de Santa Maria - UFSM, Cidade Universitária, P.0. Box: 5021, 97105-900 Santa Maria, RS, Brazil. Phone: +55 (55) 3220-8021 or 3220-8781; Fax: +55 (55) 3220-8007 - E-mail: njschuch@lacesm.ufsm.br
} 


\section{INTRODUCTION}

The magnetopause is the boundary that separates the region of space where plasmas are dominated by the Earth's magnetic field (the magnetosphere) from the region where the interplanetary magnetic field (IMF) predominates. This interface contains a current sheet - the Chapman-Ferraro current (Nishida, 1978; Russell, 1990). The magnetopause position is determined through a pressure balance. The solar wind dynamic pressure $\left(\rho \mathrm{V}^{2}\right)$ is balanced by the geomagnetic field pressure $\left(\mathrm{B}^{2} / 2 \mu_{0}\right)$ at the magnetopause location.

Interplanetary shocks are observed as sudden variations in solar wind plasma and magnetic fields. They occur when the relative difference between a fast solar wind stream (such as an interplanetary coronal mass ejection - ICME) and the slow, background solar wind stream is higher than the solar wind magnetohydrodynamics (MHD) characteristic speed - magnetosonic (Burgess, 1995; Echer et al., 2003). When the disturbance has a larger velocity than the fast mode MHD wave, a fast shock can be formed. Shock can be of the forward type, propagation away from the Sun and usually associated with ICMEs (Gosling et al., 1990; Burlaga, 1995). On the other hand, shocks can be of the fast reverse type, which is propagating toward the Sun, but is convected by the supersonic solar wind and from the point of view of spacecraft/Earth is propagating antisunward (Burlaga, 1970; Echer et al., 2003); they are mainly associated with the trailing edge of corotating interaction regions (CIRs) (Burlaga, 1995).

The plasma and magnetic field profiles through these different types of shocks are shown in Echer et al. (2003). The main difference is that, for a forward shock, all observed parameters (density, velocity, temperature, magnetic field magnitude) show a positive jump across the shock, while for a reverse shock the magnetic field, density and temperature/pressures shows a negative jump. Only velocity shows a positive jump, because the shock is being convected by solar wind. Near Earth's orbit, fast forward shocks are more common (Echer et al. 2003).

When an interplanetary shock impinges on the magnetosphere, a sudden variation in the Chapman-Ferraro current is recorded in the horizontal $(\mathrm{H})$ component of the low latitude geomagnetic field. If the shock is a fast forward one, a positive sudden impulse (SI) is recorded (Siscoe et al., 1968; Smith et al., 1986) while, if a reverse shock impinges, occurs a negative sudden impulse (Akasofu, 1964; Nishida, 1978). The positive SI due to forward shocks occurs as a result of the compressed magnetosphere and intensified magnetopause current, which cause a positive variation in the magnetic field observed at ground level.
The negative SI due to reverse shocks occurs because of the expanded magnetosphere due to the decrease in solar wind pressure.

In this work we study the effects of fast forward and reverse shocks on the SI recorded on low latitudes through the SYM-H index. We used 50 fast shocks studied by Echer et al. (2005) and 10 reverse shocks found by looking into solar wind data. Dynamic pressure variations and SI amplitude for these 2 classes of shocks/SI are compared in this paper.

\section{METHODOLOGY}

Echer et al. (2005) have studied the relation between sudden impulse amplitudes and solar wind pressure. We take from that study the 50 fast shocks observed in 2000. Solar wind data from ACE spacecraft (Stone et al., 1998) were used to calculate the SW pressure. Only the proton density was considered in the calculation of dynamic pressure $\rho V_{2}$. In addition, we have identified 10 reverse shocks occurring in solar wind during 1999-2003 using also ACE data. Upstream (1) and downstream (2) averages of solar wind/IMF parameters were calculated in two intervals around the interplanetary shock following 2 the procedure described in Echer et al. (2003).

To calculate the SI amplitude, we have used the SYM-H index (lyemori et al., 1999) from World Data Centre for GeomagnetismKyoto. This index is a high resolution (1 min) version of the Dst index. With the shock time observed at ACE, we searched at SYM-H, taking into account around 1 hour of delay for the propagation time from ACE position to Earth and look for sudden positive/negative variations in this index.

\section{RESULTS AND DISCUSSION}

Examples of positive and negative sudden impulses are presented in Figures 1 and 2. Figure 1 shows the solar wind parameters, dynamic pressure and SYM-H for the fast forward shock observed by ACE on January $11^{\text {th }} 2000$ at $\sim 13: 38$. Upstream (1) and downstream (2) intervals used to calculate upstream and downstream solar wind/IMF averages are also shown. The positive SI was observed around 14:28 UT by ground based stations. This shock had compression ratio of 1.8 (density, $n_{2} / n_{1}$ ) and 1.4 (magnetic field, $B_{2} / B_{1}$ ). The observed SI amplitude was $17 \mathrm{nT}$, while the variation the square root of dynamic pressure $\left(P_{2}^{1 / 2}-P_{1}^{1 / 2}\right)$ was $\sim 1.05 \mathrm{nPa}^{1 / 2}$, which is a result similar to the average seen by Echer et al. (2005).

Figure 2 shows the solar wind data and SYM-H index for the reverse shock observed o May 25 1999 at $~ 09: 45$ UT on 25 May 


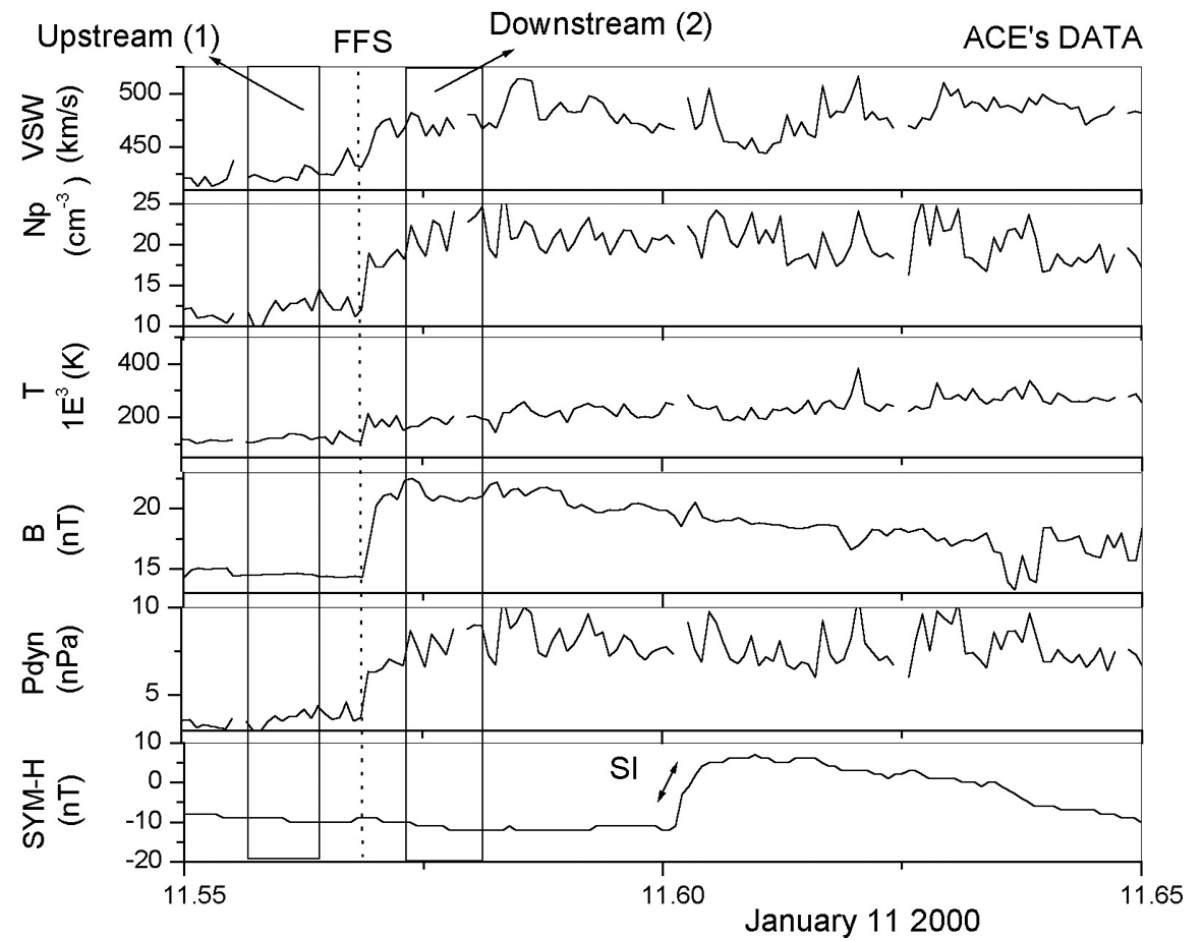

Figure 1 - Example of a fast forward shock and a positive SI, observed on January $11^{\text {th }}, 2000$. Panels are, from top: solar wind velocity, proton density and temperature, magnetic field strength, solar wind dynamic pressure and the SYM-H index.

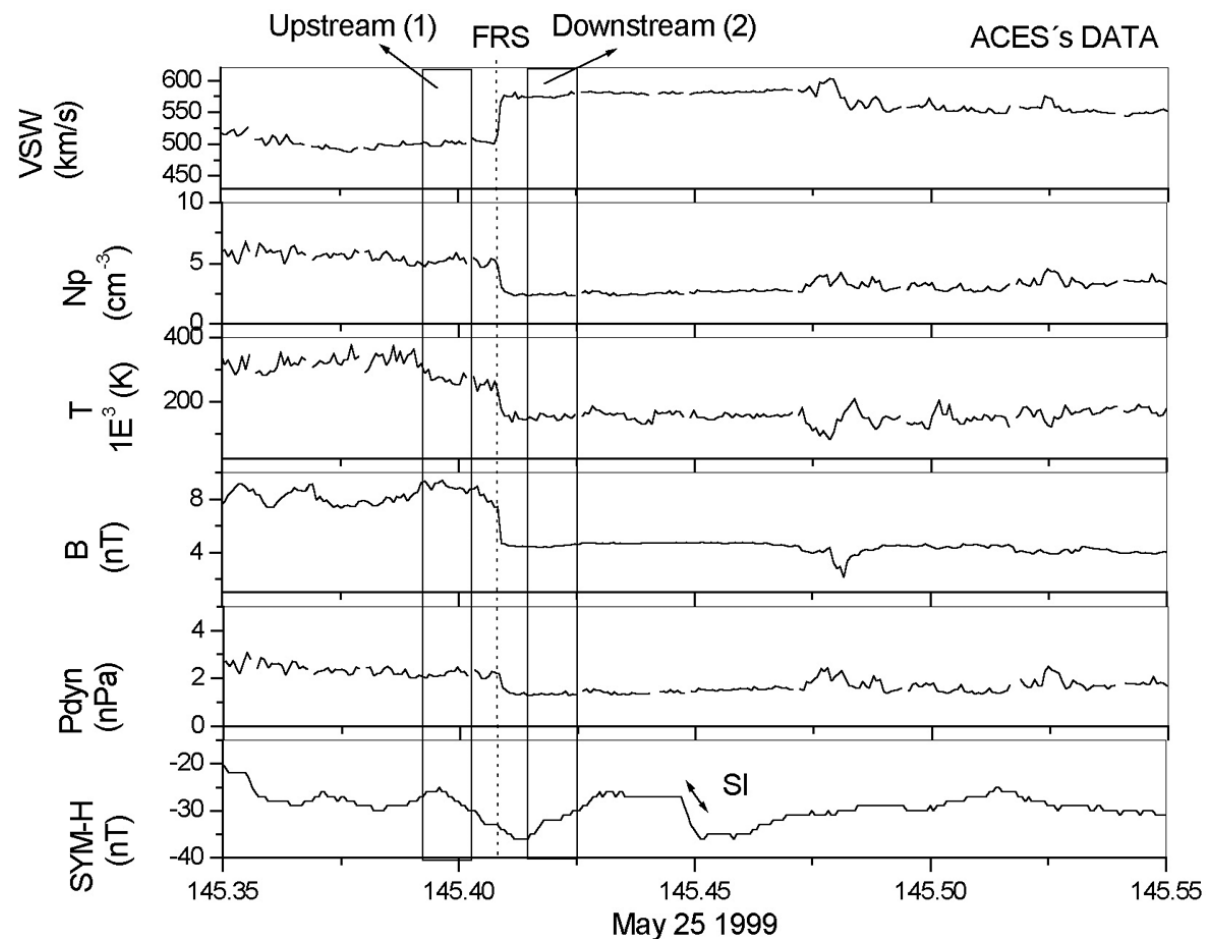

Figure 2 - Example of a fast reverse shock and a negative SI, observed on May $25^{\text {th }}, 1999$. Panels are the same as in Figure 1. 

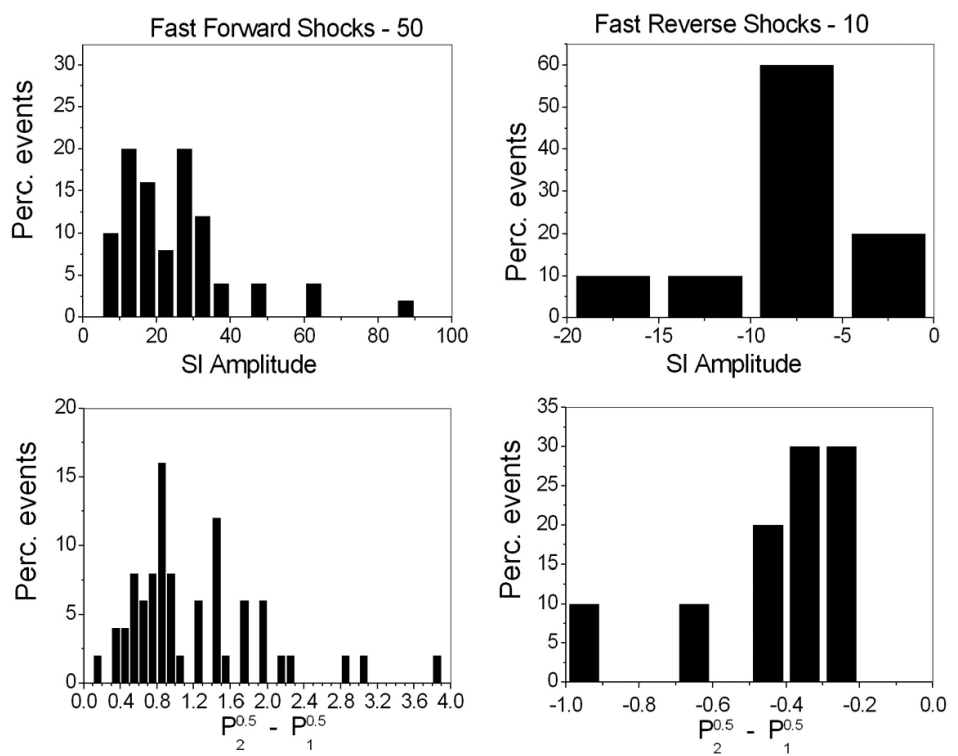

Figure 3 - Distribution of SI amplitudes and $\mathrm{P}_{2}^{1 / 2}-\mathrm{P}_{1}^{1 / 2}$ for fast forward shocks (on the left) and fast reverse shocks (on the right).

1999, by ACE. A negative SI was observed around 10:45 UT. This shock had a compression ratio of $\sim 2.0$ for density and magnetic field. The SI amplitude is $\sim-9 n T$, and the $\left(P_{2}^{1 / 2}-P_{1}^{1 / 2}\right)$ $\sim-0.29 \mathrm{nPa}^{1 / 2}$.

Notice that this type of $\mathrm{SI}$ is difficult to detect, especially if it occurs during a negative Dst variation/ring current enhancement. We can distinguish this variation during negative SYM-H values mainly because of the sudden variations in SYM-H seen during Sls.

The $\mathrm{SI}$ and $\mathrm{P}_{2}^{1 / 2}-\mathrm{P}_{1}^{1 / 2}$ distributions can be seen on Figure 3. These distributions are the normalized number of events per each SI amplitude or dynamic pressure variation range. The normalized number was obtained by dividing the number of shocks in each range interval by the total number of shocks and times 100. We can see that the magnitude of $\mathrm{SI}$ is much higher for forward shocks. Most of negative SI events had amplitude around $\sim 5-10 \mathrm{nT}$, while positive SI had magnitude around 10$30 \mathrm{nT}$. The square root dynamic pressure variation also shows that forward shocks are stronger and consequently their associated SI will have higher amplitudes.

Correlation analysis (not showed here) between SI amplitude and $\mathrm{P}_{2}^{1 / 2}-\mathrm{P}_{1}^{1 / 2}$ was performed. We have observed that the correlation is higher for fast forward shocks $(r \sim 0.84)$ than for fast reverse shocks $(r \sim 0.62)$. There is also a larger scattering of points for reverse shocks. In part, this lower correlation could be caused by the small number of points available for reverse shocks. The coefficients are more or less similar, $17.4 \mathrm{nT} / \mathrm{nPa}^{1 / 2}$ for forward shocks and $13.5 \mathrm{nT} / \mathrm{nPa}^{1 / 2}$ for reverse shocks. These values are closer to the coefficient observed for SI $x$ forward shocks during solar maximum and solar minimum (17 and $18 \mathrm{nT} / \mathrm{nPa}^{1 / 2}$ ) by Echer et al. (2005).

Finally, we can notice that dynamic pressure variations are always negative across reverse shocks. Since velocity increases and density decreases through these shocks, is theoretically possible to have cases with a positive dynamic pressure variation. This was not observed in the present study. In fact, positive dynamic pressure variations across reverse shocks should be very rare in solar wind at Earth's orbit. This is expected because the relative variation of density across shocks is much higher (2-4 times the upstream density) than the solar wind speed relative variation (typically 1.5 times the upstream values) and then the pressure variation is determined mainly by the density variation.

\section{CONCLUSION}

We have studied positive and negative low latitude sudden impulses caused by fast forward and reverse shocks. We have observed that the SI amplitude is larger for positive SI than for negative SIs, as a consequence of fast forward shocks having larger dynamic pressure variations (stronger shocks). Correlation and proportionality coefficients are lower for reverse shocks, but the proportionality with the square root variation of dynamic pressure is still followed. 


\section{ACKNOWLEDGEMENTS}

The authors would like to acknowledge for PIBIC/INPE - CNPq, ACE mission for solar wind data and Geomagnetism-Kyoto for SYM-H index.

\section{REFERENCES}

AKASOFU SI. 1964. The development of geomagnetic storms after a negative sudden impulse, Planet. Space Sci, 12: 573-578.

BURGESS D. 1995. Collisionless Shocks. In: KIVELSON MG \& RUSSELL CT (Ed.). Introduction to Space Physics. Cambridge, University Press, 129-163.

BURLAGA LF. 1970. A reverse hydromagnetic shock in the solar wind, Cosmic Electrodynamics, 1: 233-238.

BURLAGA LF. 1995. Interplanetary Magnetohydrodynamics, Oxford University Press, New York. $250 \mathrm{pp}$.

ECHER E, GONZALEZ WD, VIEIRA LEA, DAL LAGO A, GUARNIERI FL, PRESTES A, GONZALEZ ALC \& SCHUCH NJ. 2003. Interplanetary shock parameters during solar activity maximum (2000) and minimum (19951996), Braz. J. Phys., 33: 115-122.

ECHER E, GONZALEZ WD, DAL LAGO A, VIEIRA LEA, GUARNIERI FL, CLÚA DE GONZALEZ AL \& SCHUCH NJ. 2005. Interplanetary shocks and sudden impulses in solar maximum (2000) and solar minimum (1995-1996), Advances in Space Research, 36(12): 2313-2317.
GOSLING JT, BAME SJ, McCOMAS DJ \& PHILLIPS JL. 1990. Coronal mass ejections and large geomagnetic storms, Geophys. Res. Lett., 17: 901-904.

IYEMORI T, ARAKI T, KAMEI T \& TAKEDA M. 1999. Mid-latitude geomagnetic indices ASY and SYM. Data analysis center for geomagnetism and space magnetism. Graduate School of Science, Kyoto University. Available at: <http://swdcwww.kugi.kyoto-u.ac.jp/aeasy/asy.pdf>. Access on: October 19, 2005.

NISHIDA A. 1978. Geomagnetic diagnosis of the Magnetosphere, Physics and Chemistry in Space, V. 9, Springer-Verlag, New York. 256 pp.

RUSSELL CT. 1990. The magnetopause, in AGU Geophysical Monograph, 58: 439-453.

SISCOE GL, FORMISANO V \& LAZARUS AJ. 1968. Relation between geomagnetic sudden impulses and solar wind pressure changes - an experimental investigation, J. Geophys. Res., 73: 4869-4876.

SMITHEJ, SLAVIN JA, ZWICKL RD \& BAME SJ. 1986. Shocks and storm sudden commencements, In: KAMIDE Y \& SLAVIN JA (Ed.). Solar Wind Magnetosphere Coupling, Terra Scientific Publishing Company, Tokyo, $345-365$.

STONE EC, FRANDSEN AM, MEWALDT RA, CHRISTIAN ER, MARGOLIES D, ORMES JF \& SNOW F. 1998. The Advanced Composition Explorer, Space Sci. Rev., 86: 1-22.

\section{NOTES ABOUT THE AUTHORS}

Vânia Fátima Andrioli is a Physics Undergraduate Student at Federal University of Santa Maria (UFSM). She developed a project about studies of Space Weather in the PET program of UFSM, period 2003-2004. She was a Undergraduate Research of Conselho Nacional de Desenvolvimento Cientifico e Tecnológico (CNPq), from 2004 to March 2006, developing the project: "Determination of Interplanetary Shock Wave Parameters" at Southern Regional Space Research Center (CRSPE/INPE MCT). Nowadays, she is Trainee Teacher in Physics at Colégio Técnico Industrial de Santa Maria.

Ezequiel Echer. Doctor (2003) in Space Geophysics, INPE. He is a contracted researcher of the Space Geophysics Department, INPE. His doctoral thesis was a study about the geoeffectiveness of interplanetary structures. He developed a Pos-Doctoral project at the Max Planck Institute for Solar System Research, Germany, about the magnetosphere response to solar wind variations, with Cluster observations. His present research topics are: the solar wind-magnetosphere coupling, MHD shocks and discontinuities propagation in the interplanetary space/heliosphere and plasma waves observed at planetary magnetospheres.

Jairo Francisco Savian is a Physics Undergraduate Student from the Federal University of Santa Maria (UFSM), he is a Science Initiation Research Student with scholarship from the Brazilian Conselho Nacional de Desenvolvimento Cientifico e Tecnológico (CNPq), period 2003-2005, with the research project: "Identification of the interplanetary origins of Intense Geomagnetic Storms occurring from 2002 to 2003". Currently is trainee at the National Institute for Space Research (INPE) developing his activities at the Southern Regional Space Research Center (CRSPE/INPE - MCT) and at the Southern Space Observatory (SSO), São Martinho da Serra, RS, Brazil, working on data collection and analysis for the Multidirectional Muons Detector Telescope.

Nelson Jorge Schuch is graduated in Physics at Federal University of Santa Maria - UFSM, in 1972. M.Sc. (Physics) - Extra Galactic Astrophysics, University of Mackenzie, São Paulo, Brazil, in 1975. Ph.D. (Astrophysics) - University of Cambridge, Cambridge, England, in 1979. Post Doctoral Experience at Cambridge University, England, in 1979/1980. From 1980 to 1995, he worked as Senior Researcher/Vice-Director of the National Observatory - ON/MCT, in Rio de Janeiro. In 1996 he was named Coordinator of the Radioastronomy Project - RA, in the Partnership between INPE/MCT - UFSM. Nowadays he is the Head of the Southern Regional Space Research Center, from the National Institute for Space Research, INPE/MCT's Unit in Santa Maria, with its subunit the Southern Space Observatory - OES/CRSPE/INPE - MCT, in São Martinho da Serra, RS. He works in the field of Astrophysics, with emphasis in Radioastronomy/Observational Cosmology, and also on Space and Atmospheric Sciences, with emphasis in the Earth-Sun Interactions, Space Weather, Aeronomy, Space Geophysics. In his professional activities, interacted with many collaborators, with more than 669 publications. 